\title{
Non-classified type duodenal atresia: case report
}

\author{
Emrah Aydin \\ Department of Pediatric Surgery, Bahcelievler State Hospital, Istanbul, Turkey
}

\begin{abstract}
Our aim is to present a case with initial diagnosis of non-classified type duodenal atresia operated in our clinic. A patient with prenatally suspected to be duodenal atresia was explored. At laparotomy type 3 duodenal atresia was found between $2^{\text {nd }}$ and $3^{\text {rd }}$ parts of duodenum. In addition, a web was detected distal to the atresic part. Duodenoduodenostomy together with web excision was performed. He had not any additional pathology. Although duodenal atresia is a very well known pathology by pediatric surgeons, though rarely a non-classified type duodenal atresia can be encountered. Possible presence of a second atresia should be kept in mind, proximal and distal segments of the duodenum and intestinal passage must be explored carefully for the presence of second atresic segment before performing duodenoduodenostomy.
\end{abstract}

Keywords: Duodenal atresia.

$\mathrm{D}$ uodenal atresia is seen in an average of every 5000-10000 live births which is more frequent in baby girls rather than baby boys [1]. Atresia usually occurs at the second part of the duodenum $[1,2]$. In more than $50 \%$ of the cases associated congenital anomalies are seen [2].

The classification of duodenal atresia encompass a spectrum from duodenal stenosis to complete separation of proximal and distal parts of the duodenum. Besides, it is classified as pre- and postampullar based on its location relative to ampulla vateri. Rarely, through a "Y" shaped biliary ductuli, bile flow can be provided for both atresic parts [3,
4]. With our case, Type 3 duodenal atresia associated with duodenal web which is not included in the classical classification is presented.

\section{CASE REPORT}

A baby boy weighing $2930 \mathrm{~g}$ delivered via cesarean section at $36^{\text {th }}$ gestational week to a G2P2 mother was admitted to our intensive care unit with initial diagnosis of duodenal atresia. His prenatal ultrasound obtained at $29^{\text {th }}$ gestational week revealed suspect polyhydramnios and duodenal atresia. The first evaluation of his postnatal radiogram which

Received: January 30, 2015 Accepted: July 09, 2015 Online: December 25, 2015

Correspondence: Dr. Emrah AYDIN. Bahcelievler Devlet Hastanesi, Kocasinan Merkez Mahallesi, Karadeniz Caddesi, No: 48, Bahcelievler, Istanbul, Turkey. 
demonstrated a double-bubble image could not disclose any additional pathology (Figure 1). Nasogastric drainage was devoid of any evidence of bile. On postnatal $3^{\text {rd }}$ day he was operated. During laparotomy dilated stomach and first part of the duodenum were seen. Between the proximal and distal parts of the duodenum luminal integrity was not found (Figure 2). Exploration of the proximal part of the duodenum could not detect any secretion of bile. Distal part was tried to be catheterized vith $10 \mathrm{~F}$ Foley catheter and a $5 \mathrm{~F}$ Fogarthy balloon catheter so as to detect a second atresic segment and a distal duodenal web $1.5 \mathrm{~cm}$ away from atresic part was disclosed. Following excision of the web, Foley catheter could be hardly advanced up to the distal part. Air and isotonic serum delivered from duodenum up to the distal part of the bowel passed freely up to the most distal part of the duodenum. Then bilious secretion was seen to flow from the distal duodenum. Choleduct was

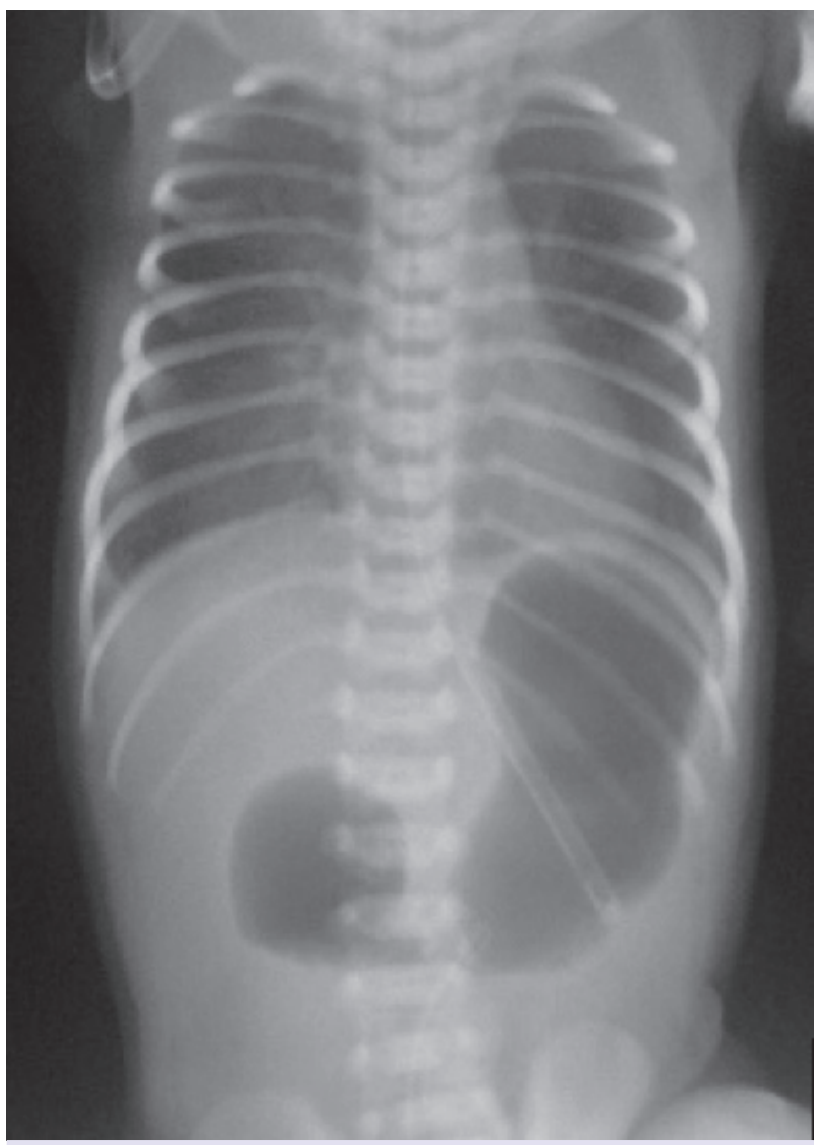

FIGURE 1. Double-bubble appearance on abdominal radiogram. retrogradely catheterized with $3 \mathrm{~F}$ ureteral stent (Figure 3). Proximal duodenum was catheterized using Foley catheter and any additional pathology could not be detected. Diamond shaped duodenoduodenostomy was performed. Postoperative $5^{\text {th }}$ day, oral nutrition was started, he could receive full dose nutrition. On postoperative $7^{\text {th }}$ day, he was discharged from the hospital with cure. He is currently at his postoperative $7^{\text {th }}$ month without any medical problem.

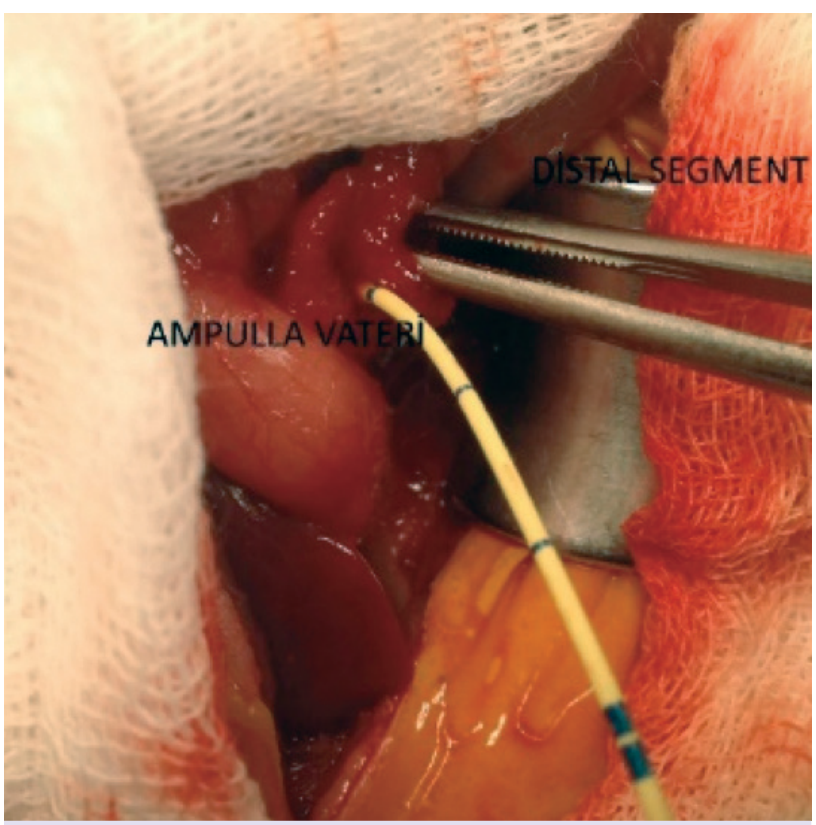

FIGURE2. Proximal and distal parts of the duodenum.

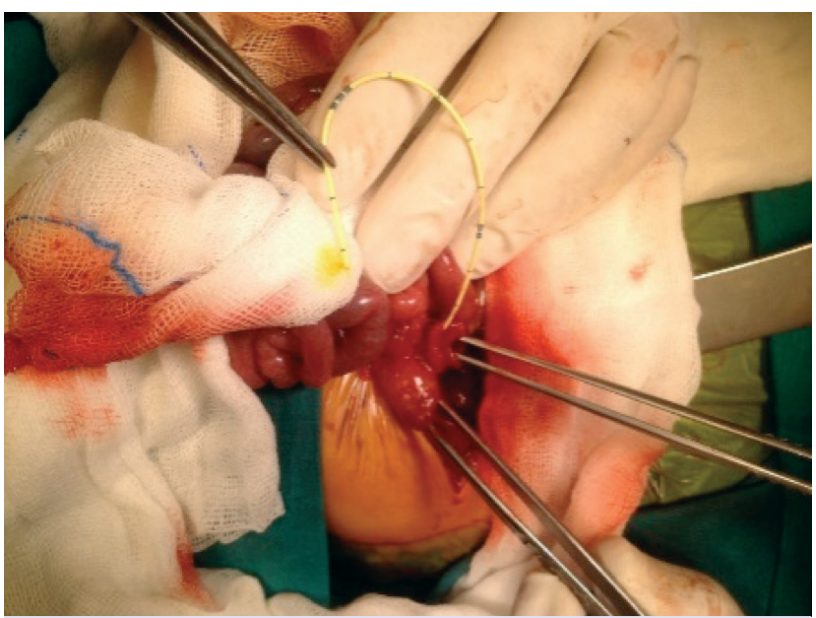

FIGURE 3. Choleduct was catheterized retrogradely using a $3 \mathrm{~F}$ ureteral stent. 


\section{DISCUSSION}

Duodenal atresia can be diagnosed beginning from the early stages of pregnancy in line with developments in diagnostic methods [4]. Gastroduodenal dilation seen in ultrasound during prenatal period is diagnostic for duodenal atresia or stenosis. Upright plain abdominal radiograms of the newborns which demonstrate double air levels and distal bowel devoid of intestinal gas have diagnostic values $[3,4]$. Also in our case, ultrasonographic examination performed at prenatal $29^{\text {th }}$ week revealed dilated stomach and duodenum in the upper abdominal quadrant. Upright abdominal radiogram obtained with suspect duodenal atresia disclosed a "double-bubble" image.

When literature series are reviewed, in more than $50 \%$ of the cases association of duodenal atresia with down syndrome, esophageal atresia, anal atresia and cardiac problems can be seen [2]. In our case, preoperative examinations could not detect any additional anomaly. However, during laparotomy, distal to the Type 3 duodenal atresia a duodenal web was detected. In a study by Escobar et al. the authors reported that all of their 137 cases with duodenal atresia were amenable to classical classification [5]. However, Lin et al. shared 20 years of their experience concerning gastrointestinal system webs, reported only presence of a duodenal atresia in only one of their 37 cases [6]. Grosfeld et al. reported duodenal web in only $1-3 \%$ of their cases with duodenal atresia [7]. In our clinic, previously two cases with double duodenal web were detected, however Type 3 duodenal atresia associated with duodenal web has not been encountered so far.

In cases with duodenal atresia surgery is the treatment modality and in technically suitable cases most frequently diamond shaped duodenoduodenostomy is preferred. Ruangtrakool et al. reported that in cases with duodenal web, web excision and duodenoplasty were performed with outcomes comparable to duodenoduodenostomy [8]. In our clinic, in both conditions we prefer duodenoduo- denostomy. In our case, also diamond shaped duodenoduodenostomy was performed and at postoperative $7^{\text {th }}$ month any complication has not been encountered so far.

Duodenal atresia is a well known pathology by pediatric surgeons, though rarely one can encounter non-classified cases. Therefore, before proceeding with duodenotomy, possibilities of concomitant second atresia or web should be kept in mind and during the procedure, presence of any atresic distal and/or proximal segment should be investigated.

Conflict of Interest: No conflict of interest was declared by the authors.

Financial Disclosure: The authors declared that this study has received no financial support.

\section{REFERENCES}

1. Kimura K, Loening-Baucke V. Bilious vomiting in the newborn: rapid diagnosis of intestinal obstruction. Am Fam Physician 2000;61:2791-8.

2. Hajivassiliou CA. Intestinal obstruction in neonatal/pediatric surgery. Semin Pediatr Surg 2003;12:241-53.

3. Miller AJW, Rode H, Cywes S. Intestinal atresia and stenosis. In: Ashkraft KW, Holcomb III GW, Murphy JP, eds. Pediatric surgery 2005. p. 416-34.

4. Rode H, Numanoglu A. Congenital atresia and stenosis of the small intestine. In: Spitz L, Coran AG, eds. Operative pediatric surgery 2006. p. 393-404.

5. Escobar MA, Ladd AP, Grosfeld JL, West KW, Rescorla FJ, Scherer LR 3rd, et al. Duodenal atresia and stenosis: long-term follow-up over 30 years. J Pediatr Surg 2004;39:867-71.

6. Lin HH, Lee HC, Yeung CY, Chan WT, Jiang CB, Sheu JC, et al. Congenital webs of the gastrointestinal tract: 20 years of experience from a pediatric care teaching hospital in taiwan. Pediatr Neonatol 2012;53:12-7.

7. Grosfeld JL, Rescorla FJ. Duodenal atresia and stenosis: reassessment of treatment and outcome based on antenatal diagnosis, pathologic variance, and long-term follow-up. World J Surg 1993;17:301-9.

8. Ruangtrakool R, Mungnirandr A, Laohapensang M, Sathornkich C. Surgical treatment for congenital duodenal obstruction. J Med Assoc Thai 2001;84:842-9. 